\title{
Concussion in Athletes: From Pathophysiology to Current Guidelines and Recommendations
}

\author{
Sharon L. Moy, DO, Family Medicine OGME-3 \\ Advocate BroMenn Medical Center, Normal, IL
}

\author{
KEYWORDS: \\ Concussion \\ Symptoms \\ Neuropsychological testing \\ BESS \\ Return to play
}

Forty-seven states and Washington D.C. have passed legislation in protecting student-athletes, but concussions still occur. Symptoms can involve somatic, cognitive, and behavioral disturbances. Moreover, many athletes underreport their symptoms. Currently, the Concussion Recognition Tool (CRT) and Sports Concussion Assessment V.3 (SCAT3) are used to quickly identify concussed players. There are several modalities that can help augment a clinician's decision in deciding when an athlete can return to play.

\section{INTRODUCTION}

The Zackery Lystedt Law was signed on May 2009. The law is named for Zackery Lystedt who, in 2006, suffered a brain injury following his return to a middle school football game after sustaining a concussion. This law requires coaches, parents, and athletes be educated about concussion and sign an informational sheet. ${ }^{1,2}$ Since April 23rd, 2013, 47 states and Washington D.C have passed laws protecting student-athletes from returning to play too soon after suffering a concussion. ${ }^{3}$ But still, it is estimated between 1.6 and 3.8 million sportrelated concussions occur each year in the United States. ${ }^{4}$ Out of which, the highest overall injury rate occurred in football, wrestling, soccer, and girls' basketball, according to the Centers for Disease Control and Prevention. ${ }^{5}$

Concussion is defined as a complex process that involves traumatic biomechanical forces either from the head, face, neck or elsewhere from the body that gets transmitted to the brain. ${ }^{6}$ There are several definitions that fit into the spectrum of head injuries besides concussion, which include postconcussion syndrome, prolonged postconcussion syndrome, and chronic traumatic encephalopathy. The difference between them is time. Concussion symptoms usually resolve in 7-10 days. ${ }^{6}$ Anything beyond this time frame falls into postconcussion syndrome. Per the $4^{\text {th }}$ edition of the Diagnostic and Statistics Manual, cognitive deficits in attention or memory must be present along with at least 3 or more of the following symptoms: fatigue, sleep disturbance, headache, dizziness, irritability, affective disturbance, apathy or personality change. ${ }^{7}$ In prolonged postconcussion

Address correspondence to: Sharon Moy, DO, 1300 Franklin Avenue, Suite 140, Normal, IL 61761; Email: Sharon.Moy@advocatehealth.com 1877-5773X/\$ - see front matter. @ 2014 ACOFP. All rights reserved. syndrome, symptoms last greater than 6 months or more. ${ }^{8}$ Last but not least, chronic traumatic encephalopathy is defined as a progressive neurodegenerative syndrome caused by episodic and repetitive blunt forces to the head that allows the transfer of deceleration/acceleration forces to the brain. This can cause a spectrum of mood disorders, neuropsychiatric disturbance, and cognitive impairment. ${ }^{9}$

\section{PATHOPHYSIOLOGY}

The frontal and temporal lobes are particularly vulnerable to the mechanical forces experienced in a concussion. ${ }^{10}$ Metabolically, the proposed mechanism described by Hovada and his team involves cells immediately injured from the mechanical force are exposed to dramatic shifts in both intracellular and extracellular environments. ${ }^{11}$ This results in excitatory amino acid induced ionic shifts with increased $\mathrm{Na}+\mathrm{K}+$ ATPase activation causing hyperglycolysis. The net effect leads to an increase in energy demand with a decrease in cerebral blood flow. ${ }^{11}$ Figure 1 describes the mechanism. Eventually, the blood brain barrier is disrupted, which leads to secondary brain injury that affects the cerebral cortex. If repetitive head injuries occur, tau proteins can be deposited, and these proteins have been associated with Alzheimer's Disease. ${ }^{9,12}$

\section{SIGNS/SYMPTOMS}

Each concussion is unique. Duhaime found that many players had a delayed onset of symptoms from the initial impact. ${ }^{13}$ Acute symptoms may start with cognitive changes that include loss of consciousness, amnesia or confusion/ disorientation with progression to somatic complaints that include nausea, vomiting, dizziness and visual disturbances. The late sequela from a concussion can include somatic complaints such as headache, fatigue, dizziness, and lethargy. In addition, behavioral symptoms have also been reported such as changes in mood, anxiety, depression, 


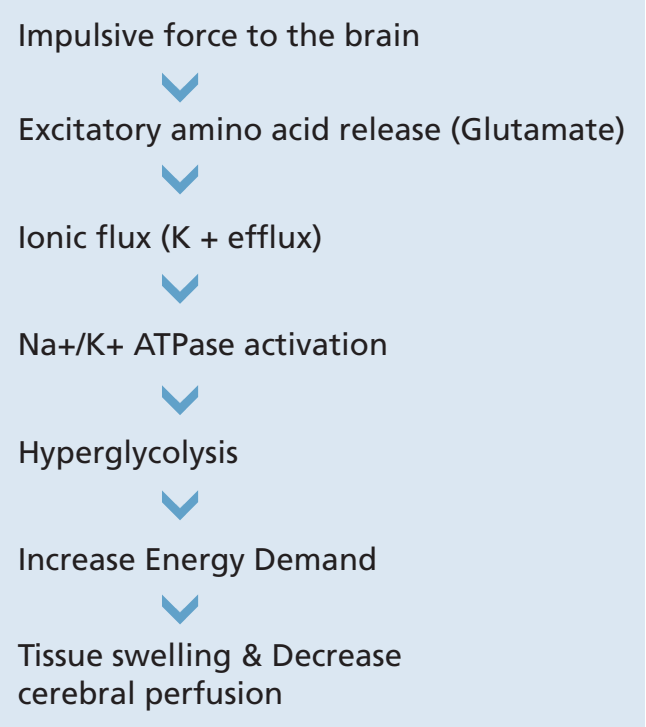

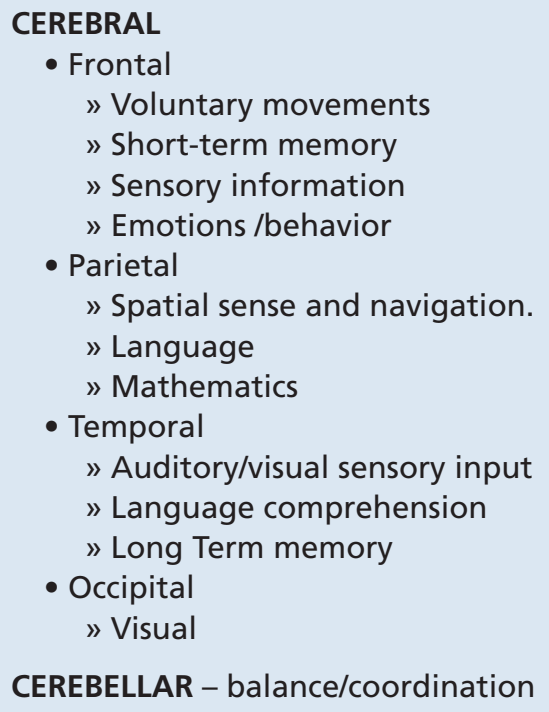

Figure 1: Biomechanical Mechanism

sleep disturbances, and irritability. A study by Makdissi followed 88 Australian football players and described their progression of symptoms as seen in Table $1 .{ }^{14}$ Table 2 provides a summary of signs/symptoms. Given with variability of symptoms, some may overlap between acute and chronic phases. In addition, Collins demonstrated that the presence of amnesia, prolonged disorientation greater than five minutes, and not the loss of consciousness appeared predictive of symptom and neurocognitive deficits, which necessitated physician referral and a more thorough neurologic evaluation. ${ }^{10}$

\section{EVALUATION}

On game day, athletes underreport their symptoms just to stay in the game. A study by Echlin demonstrated the interaction of coaches, athletes, athletic trainers, and team doctors. ${ }^{15}$ His team found that athletes resisted describing their symptoms to the physicians. Numerous coaches overruled the team physician's recommendations and used intimidation tactics to keep the player in the game despite having concussion symptoms. Similar events also occurred with athletic trainers. $^{15}$

When an athlete sustains a head injury, the player is immediately removed from the game. A primary survey of airway, breathing, and circulation is performed with the cervical spine in neutral position. Sideline assessment includes: obtaining history of mechanism, observation, palpation, range of motion, strength and functional tests including a neurologic examination. One can ask questions regarding memory such as moment of impact, opposing team's name, what foods were eaten at lunch etc. To check for

Table 1: Progression of Symptoms ${ }^{14}$

\begin{tabular}{|c|c|c|c|c|}
\hline Clinical Feature & $\begin{array}{c}\mathbf{N} \\
\text { (number of } \\
\text { players) }\end{array}$ & $\mathrm{N} \%(95 \% \mathrm{Cl})$ & $\begin{array}{c}\text { Mean Duration } \\
(95 \% \mathrm{CI})\end{array}$ & Range \\
\hline Amnesia & 33 & $37.5(27.4-47.6)$ & $1.6 \mathrm{hrs}(0.5-2.7)$ & $0-12 \mathrm{hrs}$ \\
\hline Confusion / disorientation & 55 & $62.5(52.4-72.6)$ & $2.1 \mathrm{hrs}(0.3-4.0)$ & $0-48 \mathrm{hrs}$ \\
\hline Dizziness, unsteadiness & 35 & $39.8(30.0-50.0)$ & $27.6 \mathrm{hrs}(16.2-38.9)$ & $0-120 \mathrm{hrs}$ \\
\hline Headache & 77 & $87.5(80.6-94.4)$ & 44.7 hrs (35.1-52.2) & $0-240 \mathrm{hrs}$ \\
\hline Sleep Disturbance & 23 & $26.1(17.0-35.3)$ & $55.8 \mathrm{hrs}(34.5-77.1)$ & $0-240 \mathrm{hrs}$ \\
\hline Fatigue, lethargy, "fogginess" & 33 & $37.5(27.4-47.6)$ & 58.2 hrs (45.6-70.9) & $0-144 \mathrm{hrs}$ \\
\hline
\end{tabular}


Table 2: Signs/Symptoms 5 , 6, 8,10,14

\begin{tabular}{|l|l|l|}
\hline Somatic & Cognitive & Behavioral \\
\hline $\begin{array}{l}\text { Acute or Chronic } \\
\text { - Nausea }\end{array}$ & Acute & Chronic \\
- Vomiting & Loss of & - Anxiety/ \\
- Dizziness & - Ponsciousness & - Depression \\
- Balance/ & disorientation & - Irritability \\
coordination & - Posttraumatic & - Sleep \\
issues & disturbance \\
- Visual & amnesia & \\
disturbances & Chronic & \\
- Photophobia & - Mental Fog & \\
- Phonophobia & & \\
- Fatigue & & \\
- Lethargy & & \\
\hline
\end{tabular}

anterograde amnesia, one can ask three unrelated words to be tested at 10-15 minute intervals. ${ }^{16}$ The standard questions of time, place, and person have been shown to be unreliable and should not be used. ${ }^{6}$

To determine the absence or presence of concussion, there are several checklists available. They include the Concussion Recognition Tool (CRT) and the Sports Concussion Assessment Tool V.3 (SCAT3). SCAT3 incorporates both the Maddocks' questions and the Standardized Assessment of Concussion (SAC). Once an athlete has been identified from either questionnaire, they are not allowed to return to the game on the same day. ${ }^{6}$ The athlete is further evaluated with Balance Error Scoring System (BESS) and neuropsychological (NP) tests. Both of which are completed on an outpatient basis.

BESS consists of 6 assessments that include 3 different stances (single, double, and tandem) on firm and unstable surfaces. Each position is held for 20 seconds, while the athlete's hands are on their iliac crests and their eyes are closed. One error point is given for each error with a maximum of 10 points. ${ }^{17}$ Table 3 lists the errors. Scores do increase with age, ankle instability, and with external ankle bracing. The average BESS score after a concussion is 17 errors (range, 15-19), compared with 10 errors at baseline. The average pre-fatigue score is 11.6 errors with 15.8 errors post-fatigue (range, 8.08-26.8). ${ }^{18}$

There are several computerized NP tests used to track cognitive recovery. They include: ImPACT, CogSport, and Headminder Concussion Resolution Index. Table 4 provides a summary of each NP test. Of note, NP tests provide prognostic information and do not change the management of athletes who are symptomatic at rest or with exercise. ${ }^{20}$ In addition, computerized NP tests do not test for verbal-auditory memory or auditory processing functions. ${ }^{21}$

\section{Table 3: Balance Error Scoring System ${ }^{17}$}

- Hands lifted off iliac crests

- Opening eyes

- Step, stumble or fall

- Moving hip into more than 30 degrees of flexion or abduction

- Lifting forefoot or heel

- Remaining out of testing position for more than 5 seconds

Table 4: Summary of Neuropsychological Testing

\begin{tabular}{|l|l|}
\hline Test & Description \\
\hline ImPACT & $\begin{array}{l}\text { Comprised of three general sections that } \\
\text { include demographics, the Post-Concussion } \\
\text { Symptom Scale (PCSS), and neurocognitive } \\
\text { modules. Verbal memory, visual memory, } \\
\text { visual processing speed, and reaction time } \\
\text { composite scores are then determined } \\
\text { from these three sections. }\end{array}$ \\
\hline CogSport & $\begin{array}{l}\text { Standard computer hardware using two } \\
\text { designated keyboard response buttons } \\
\text { ("K" and "D" for "YES" and "NO"), } \\
\text { simple textual instructions and game-like } \\
\text { playing-card stimuli in five tasks assessing } \\
\text { psychomotor processing speed, decision } \\
\text { making, divided attention, memory and } \\
\text { learning. }\end{array}$ \\
\hline $\begin{array}{l}\text { Headminder } \\
\text { Concussion }\end{array}$ & $\begin{array}{l}\text { 25-minute test given in both pre-season } \\
\text { and after head injury. This measures } \\
\text { reaction time, memory, and other } \\
\text { neurocognitive functions. From the } \\
\text { short subtests given, three factors are } \\
\text { empirically derived: 1. Simple reaction } \\
\text { time, 2. Complex reaction time, and 3. } \\
\text { Processing speed. }{ }^{19}\end{array}$ \\
\hline
\end{tabular}

In a study by Comper, his team performed a systematic review that evaluated the methodological quality of NP tests, where 43 studies out of 349 were evaluated. From 2003 to the present, computerized NP tests were used more than paper and pencil testing as demonstrated in 15 of the studies, while eight continued paper and pencil testing. Overall, his team found deficiencies in selection bias, sex differences, a lack of definition of concussion, and that the studies focused mostly on football. ${ }^{22}$

Another study by Covassin focused on the role of age and sex in neurocognitive testing using ImPACT and BESS. Female athletes performed worse than male athletes on visual memory (mean, $65.1 \%$ and $70.1 \%$ respectively; $\mathrm{P}=.049$ ) and reported more symptoms (mean 14.4 and 10.1) after concussion ( $\mathrm{P}=$ .035). High school athletes performed worse than collegiate athletes on verbal (mean $78.8 \%$ and $82.7 \%, \mathrm{P}=.001$ ) and visual memory (mean, $65.8 \%$ and $69.4 \%, \mathrm{P}=.01$ ). High school male athletes were still impaired on verbal memory seven days after concussion compared with collegiate athletes $(\mathrm{P}=.001)$. High school male athletes scored worse on BESS 
Table 5: Types of Treatment for Post-Concussion Syndrome ${ }^{26}$

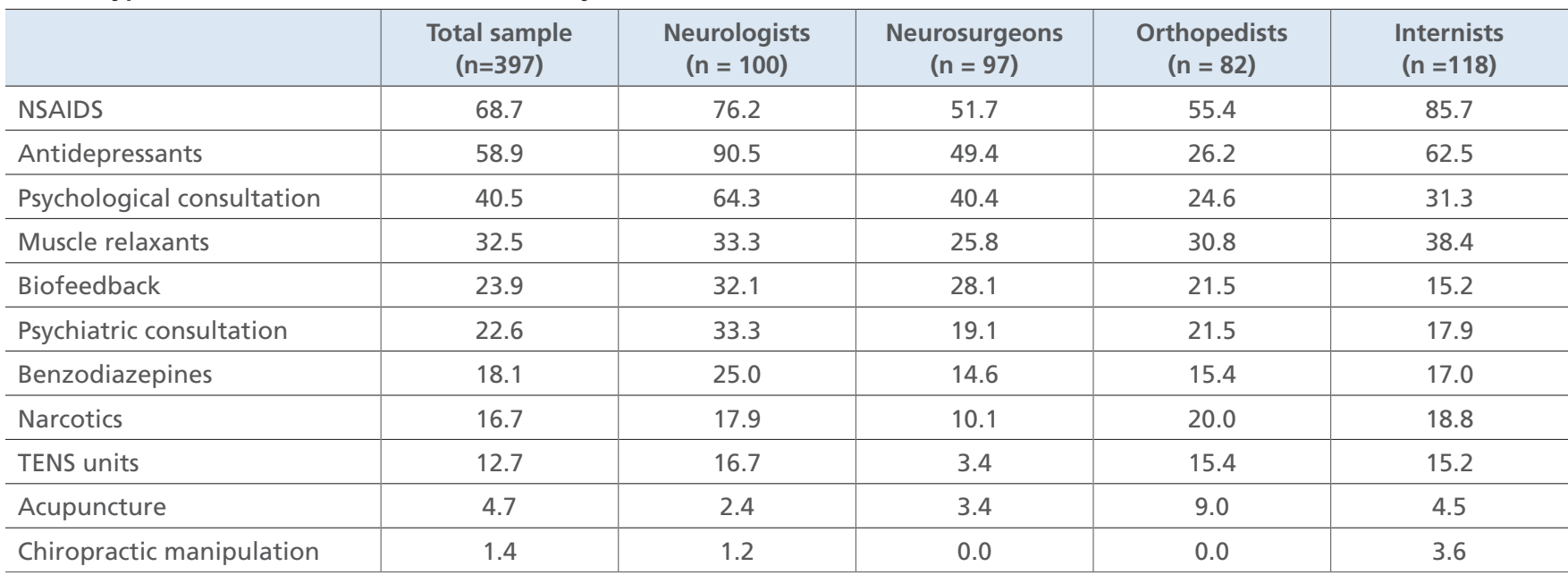

than college male athletes (mean, 18.8 and 13.0, $\mathrm{P}=.001$ ). College female athletes scored worse on BESS than high school female athletes (mean, 21.2 and 16.9, $\mathrm{P}=.001$ ). ${ }^{1}$

Overall, there are no direct tests that can determine the outcome from a concussion. The Zurich guidelines stress that there is no need for baseline NP tests for all athletes and there is insufficient evidence for routine use. ${ }^{6}$ Ideally, NP tests should be performed when an athlete is asymptomatic, but if done in the early stages from the time of injury, they maybe of value to track neurocognitive recovery. ${ }^{6}$ With the use of NP tests and BESS, they can help guide clinicians to augment their clinical decision in treating athletes. ${ }^{14,23}$ If NP test or formal balance assessment is not used, a conservative approach should be employed before returning to play. ${ }^{6}$ In the end, the physician makes the determination when an athlete can return to play.

In regards to imaging, CT scan and MRI are generally insensitive to measuring the subtle effects in a concussion. ${ }^{6}$ In cases of prolonged disturbances of the conscious state, focal neurological deficits, worsening clinical status, or suspicion of an intracerebral lesion, imaging is then warranted. ${ }^{6}$

\section{TREATMENT}

The athlete needs to rests their brain, where concentration and attention are minimized. Examples include but not limited to: reading, schoolwork, video games (television, computers, and handhelds), text messaging, and working. ${ }^{6}$ If a studentathlete returns to school, their school workload needs to be adjusted to not provoke symptoms such as having a later start date, taking frequent breaks, studying in a quiet environment, having alternate forms of examinations and smaller homework assignments. ${ }^{24}$ In addition, if dizziness is still present, the student should be able to leave before the bell to transition to their next class by avoiding the large crowds. ${ }^{24}$ Physical rest also needs to be achieved by limiting further contact to the head and abstaining from strenuous exercises such as aerobic activities and resistance training. ${ }^{25}$ The modified routine should remain in place until symptom free.

Moreover, NSAIDS are to be avoided, since they may mask symptoms and complicate recovery time. ${ }^{25}$ In the past, postconcussion symptoms were treated with medications and other modalities as shown in Table 5. Today, review of the literature demonstrates there is no standard approach in treatment of symptoms. ${ }^{25,26}$ Per the Zurich guidelines, there are two instances where medications can be allowed (1) management of specific or prolonged symptoms and (2) modifying the underlying pathophysiology of a condition to shorten the duration of the symptom. ${ }^{6}$ If dizziness still persists, vestibular rehabilitation has been shown to improve vertigo and gait. ${ }^{11}$ If postconcussion symptoms persists for 3 to 6 weeks or more, a stepwise exercise program and rehabilitation may be required. ${ }^{7}$

Osteopathic manipulation can also be another form of treatment to help with somatic dysfunctions at the cervical and thoracic regions by using muscle energy or high velocity, low-amplitude (HVLA) techniques. ${ }^{27}$ In addition, the Muncie technique can be used to help with vertigo by inserting a gloved finger over the palatine tonsil and applying a circular traction, while at the same time applying a lateral force. The traction that is created helps break up adhesions in the Eustachian tube. ${ }^{28}$ 
Table 6: Return to Play Protocol ${ }^{6}$

\begin{tabular}{l|l|l}
\hline Rehabilitation Stage & Functional Exercise & Objective \\
\hline 1. No activity. & Complete physical and cognitive rest. & Recovery. \\
\hline 2. Light aerobic exercise. & $\begin{array}{l}\text { Walking, swimming, or stationary cycling. Goal } \\
\text { is to keep intensity <70\% maximum predicted } \\
\text { heart rate. }\end{array}$ & Increase heart rate. \\
\hline 3. Sport-specific exercise. & $\begin{array}{l}\text { Skating drills in ice hockey, running drills in } \\
\text { soccer. No head impact activities. }\end{array}$ & Add movement. \\
\hline 4. Non-contact training drills. & Progression to more complex training drills. & Exercise, coordination, and cognitive load. \\
\hline 5. Full contact practice. & $\begin{array}{l}\text { Participation in normal training activities after } \\
\text { medical clearance. }\end{array}$ & $\begin{array}{l}\text { Restore confidence and assess functional skills } \\
\text { by coaching staff. }\end{array}$ \\
\hline 6. Return to play. & Normal game play. & \\
\hline
\end{tabular}

\section{RETURN TO PLAY}

Once concussion symptoms have resolved, NP results show improvement, and that the athlete is not taking medications that may mask symptoms, the athlete follows a graduated return to play protocol. There are six steps, and each step requires a minimum of 24 hours with the athlete remaining asymptomatic before progressing to the next step. ${ }^{6}$ Table 6 lists each step in the protocol.

\section{CONCLUSION}

The Zurich guidelines are the cornerstone in concussion management at this time. Even with the current guidelines and legislation, the most devastating complication in any concussion is second-impact syndrome. This occurs when an athlete returns to play too soon before their concussion resolves and receives another concussion. From that second impact, rapid deterioration in neurologic status can lead to death within minutes due to cerebral edema and herniation. ${ }^{29}$ It is prudent when an athlete is concussed, the player is taken out of the game and not be allowed to return to play on the same day. Through a period of physical and cognitive rest, the athlete can then be transitioned back into their school workload that has been adjusted for them. In the end, this can lead to a safer return to play once a physician deems the athlete is ready to participate in sports again. 


\section{REFERENCES}

1. Shenouda C, Hendrickson P, Davenport K, et al: The effects of concussion legislation one year later - what have we learned: a descriptive pilot survey of youth soccer player associates. PM R. 2012;xx:1-9.

2. Tomei K, Doe C, Prestigiacomo C, et al: Comparative analysis of state-level concussion legislation and review of current practices in concussion. Neurosurg Focus. 2012;33:1-9.

3. Barlo Frollo J. See where your state stands on concussion law. Available at: USA Football. http://usafootball.com/news/featured-articles/seewhere-your-state-stands-concussion-law. Accessed May 9, 2013.

4. Covassin T, Elbin R, Harris W, et al: The role of age and sex in symptoms, neurocognitive performance, and postural stability in athletes after concussion. Am J Sports Med 2012;40:1303-1312.

5. Lincoln A, Caswell S, Almquist J, et al: Trends in concussion incidence in high school sports. A prospective 11-year study. Am J Sports Med. 2011;39:958-963.

6. McCory P, Meeuwisse W, Aubry M, et al: Consensus statement on concussion in sport: the $4^{\text {th }}$ international conference on concussion in sport held in Zurich, November 2012. Br J Sports Med 2013;47:250258.

7. Leddy J, Sandhu H, Sodhi V, et al: Rehabilitation of concussion and post-concussion syndrome. Sports Health. 2012;4:147-154.

8. Evans R. Post-traumatic headaches. Neurol Clin N Am. 2004;22:237249.

9. Dashnaw M, Petraglia A, Bailes J. An overview of the basic science of concussion and subconcussion: where are we and where are we going. Neurosurg Focus. 2012;33:1-12.

10. Collins $M$, Iverson $G$, Lovell $M$, et al: On-field predictors of neuropsychological and symptom deficit following sports-related concussion. Clin J Sport Med. 2003;13:222-229.

11. Lovell M. The management of sports-related concussion: current status and future trends. Clin Sports Med. 2009;28:95-111.

12. Stern R, Riley $D$, Daneshvar $D$, et al: Long-term consequences of repetitive brain trauma: chronic traumatic encephalopathy. PM R. 2011;3:S460-\$467.

13. Duhaime A, Beckwith J, Maerlender A, et al: Spectrum of acute clinical characteristics of diagnosed concussions in college athletes wearing instrumented helmets. J Neurosurg. 2012;117:1092-1099.

14. Makdissi M, Darby D, Maruff $P$, et al: Natural history of concussion in sport: markers of severity and implications of management. Am J Sports Med. 2010;38:464-471.
15. Echlin P. A prospective study of physician-observed concussion during a varsity university ice hockey season. Part 1 of 4 . Neurosurg Focus. 2012;33(6):E1.

16. Guskiewicz K and Broglio S. Sport-related concussion: on-field and sideline assessment. PM R. 2011;22:603-617.

17. Guskiewicz K. Balance assessment in the management of sport-related concussion. Clin Sports Med. 2011;30:89-102.

18. Bell D, Guskiewicz K, Clark M, et al: Systematic review of the balance error scoring system. Sports Health 2011;3:287-295.

19. HeadMinder CRI - How It Works. http://www.headminder.com. Accessed January 21, 2013

20. Shrier I. Neuropsychological testing and concussions: a reasoned approach. Clin J Sport Med. 2012;22:211-213.

21. Coppel D. Use of neuropsychological evaluations. PM R. 2011;22:653664.

22. Comper P, Hutchison M, Magrys S, et al: Evaluating the methodological quality of sports neuropsychology concussion research: a systematic review. Brain Inj. 2010;24:1257-1271.

23. Barlow M, Schlabach D, Peiffer J, et al: Differences in change scores and the predictive validity of three commonly used measures following concussion in the middle school and high school aged population. Int J Sports Phys Ther. 2011;6:150-157

24. 24. Sady M, Vaughan C, Gioia G. School and the concussed youth: recommendations for concussion education and management. PM R. 2011;22:701-719.

25. Meehan III W. Medical therapies for concussion. Clin Sports Med. 2011;30:115-124.

26. Mittenberg W, Canyock E, Condit D, et al: Treatment of postconcussion syndrome following mild head injury. J Clin Exp Neuropsychol. 2001;23:829-836.

27. Channell M, Mueller L, Hahn R. Management of chronic posttraumatic headache: a multidisciplinary approach. J Am Osteopath Assoc. 2009;109:509-513

28. Channell M. Modified muncie technique: osteopathic manipulation for eustachian tube dysfunction and illustrative report of case. J Am Osteopath Assoc. 2008;108:260-263.

29. Laker S. Return to play decisions. PM R. 2011;22:619-634. 